\title{
A construção da nação na América Latina, um processo interrompido: bloqueios internos e externos
}

\author{
The construction of the nation in Latin America, an interrupted process: \\ internal and external blockades
}

\section{Carlos Serrano Ferreira e Wilson Vieira ${ }^{b}$}

Resumo O objeto deste trabalho é a análise da relação entre os projetos de construção da nação e as tentativas de superação do subdesenvolvimento na América Latina diante dos desafios colocados pelas transformações na economia mundial no período 19702010, apresentando os bloqueios internos e externos. Os objetivos são: i) estudar a inserção dependente latino-americana como caso exemplar das Relações Internacionais enquanto ciência de fronteira; ii) compreender os motivos das dificuldades de se construir a nação e superar o subdesenvolvimento na América Latina, principalmente a partir da década de 1970, dadas as transformações da economia mundial sob a hegemonia dos EUA e a manutenção de estruturas internas de dependência; iii) mostrar que o pensamento de Celso Furtado, a Teoria Marxista da Dependência (TMD) e a economia política do sistema-mundo são ferramentas válidas de explicação dessas dificuldades, ao colocarem o papel da hegemonia dos EUA para a compreensão do que ocorre na América Latina nesse período; iv) mostrar a partir de Ruy Mauro Marini os limites da burguesia latino-americana na consolidação da nação. A hipótese de trabalho é que os projetos de construção da nação na América Latina sofrem dificuldades cada vez maiores, dados os sucessivos golpes de Estado e as transformações da economia mundial sob o comando norte-americano, e o aprofundamento do caráter dependente da burguesia regional.

Palavras-chave pensamento de Celso Furtado; Teoria Marxista da Dependência; economia política do sistema-mundo; nação; desenvolvimento da América Latina.

a Cientista político, vice-coordenador do Laboratório de Estudos sobre Hegemonia e Contra-Hegemonia da Universidade Federal do Rio de Janeiro (LEHC/UFRJ) e doutorando em Ciência Política pelo ISCSP da Universidade de Lisboa.

b Economista, professor do Instituto de Economia da UFRJ, pesquisador do Laboratório de Estudos de Hegemonia e Contra-Hegemonia (LEHC) da UFRJ e do Laboratório de Estudos Marxistas (LEMA) da UFRJ. 
Abstract The purpose of this paper is to analyze the relationship between the nation's construction projects and the attempts to overcome underdevelopment in Latin America in the face of the challenges posed by the transformations in the world economy in the period 1970-2010, presenting the internal and external blocks. The objectives are: (i) to study the Latin American dependent insertion as an exemplary case of International Relations as frontier science; (ii) to understand the reasons for the difficulties of building the nation and overcoming underdevelopment in Latin America, especially since the 1970s, given the transformations of the world economy under US hegemony and the maintenance of internal structures of dependency; iii) to show that Celso Furtado's thinking, the Marxist Dependency Theory (TMD), and the political economy of the world-system are valid tools for explaining these difficulties by placing the role of US hegemony as fundamental to understand what happens in Latin America in this period; iv) to show from the work of Ruy Mauro Marini, the limits of Latin American bourgeoisie on the consolidation of the nation. The working hypothesis is that the construction projects of the nation in Latin America are increasingly difficult to achieve, given the successive coup d'état and the transformations of the world economy under US command, and the deepening of the dependent character of the regional bourgeoisie.

Keywords Celso Furtado's thought; Marxist Theory of Dependency; political economy of the world-system; nation; development of Latin America

\section{INTRODUÇÃO}

O objeto deste trabalho é a relação entre os projetos de construção da nação e as tentativas de superação do subdesenvolvimento na América Latina diante dos desafios colocados pelas transformações na economia mundial no período 19702010, apresentando os bloqueios internos e externos. Esta questão se inscreve diretamente nas preocupações temáticas do campo das Relações Internacionais. O problema nacional, de construção em diversas realidades e entidades estatais de diferentes naturezas, ligou-se desde o princípio ao próprio sistema internacional. A certidão de nascimento do mesmo, Vestfália, é a consagração da soberania nacional.

A construção do Estado-nação na Europa Ocidental produziu, ao mesmo tempo, um espaço interno de relações de poder, mas também criou o campo das Relações Internacionais. As diferentes conformações da relação entre Estado e Nação dão a tônica prática de diferenças entre entidades estatais nacionais, entidades plurinacionais - como os impérios Autro-Húngaro, Otomano e Russo - e nações sem Estado nas Relações Internacionais. Essa dialética entre Estados e Nações gera alguns dos desafios centrais do cenário contemporâneo, como a questão palestina, 
e marca a política externa de potências centrais - como o separatismo para o Estado Espanhol e a Federação Russa.

Também no âmbito teórico, essa dialética está no centro da disciplina das Relações Internacionais. Apesar de haver um consenso geral acerca do papel central do Estado nas relações internacionais, o debate entre as diversas correntes e perspectivas se centram, entre outras coisas, na discussão sobre o campo de autonomia da soberania nacional frente a forças não-estatais e não-nacionais, como os grandes conglomerados transnacionais.

Acreditamos que esta questão nos países dependentes latino-americanos é exacerbada. De fato, a realidade destes demonstra claramente o caráter das Relações Internacionais enquanto fronteira das ciências sociais, talvez como nenhum outro exemplo. A inserção internacional da região conformou e foi conformada ao mesmo tempo pelo processo de consolidação e de obstrução à construção do Estado-nação. Não se entenderá jamais os limites à atuação soberana internacionalmente - que a dependência nega em conteúdo, mas afirma na forma - que esses países possuem estruturalmente, sem apontar e estudar essa inserção na fronteira com outros campos das ciências humanas, como a ciência política, a economia e a sociologia. As características internas desses Estados são determinadas pela sua posição internacional e, dialeticamente, esta é reforçada pelas características internas. Não se entende a inserção dependente regional - e inclusive suas dificuldades de integração interestatal - sem entender o papel da estrutura de poder construída pela burguesia dependente que, sendo associada, explica, por sua vez, o próprio caráter dependente e os limites estruturais internos de desenvolvimento em cada entidade estatal da região.

Frente a isto, os nossos objetivos são: i) estudar a inserção dependente latino-americana como caso exemplar das Relações Internacionais enquanto ciência de fronteira das ciências sociais; ii) compreender os motivos das dificuldades de se construir a nação e superar o subdesenvolvimento na América Latina, principalmente a partir da década de 1970, dadas as transformações da economia mundial sob a hegemonia dos EUA e a manutenção de estruturas internas de dependência; iii) mostrar que o pensamento de Celso Furtado, a Teoria Marxista da Dependência (TMD) e a economia política do sistema-mundo são ferramentas válidas de explicação dessas dificuldades, ao colocarem o papel da hegemonia dos EUA para a compreensão do que ocorre na América Latina nesse período; iv) mostrar, a partir de Ruy Mauro Marini, os limites da burguesia latino-americana na consolidação da nação. Nossa hipótese é de que os projetos de construção de nação na América Latina, fortemente atrelados aos projetos de superação do subde- 
senvolvimento comandados pelo Estado e iniciados, de maneira geral, a partir da década de 1930 e intensificados na década de 1950, sofrem dificuldades cada vez maiores para serem concretizados, dados os sucessivos golpes de Estado a partir de 1964, a mudança da política dos EUA para a América Latina, as transformações da economia mundial sob o comando norte-americano e o aprofundamento do caráter dependente da burguesia regional.

\subsection{CARÁTER DA NAÇÃO E DOS NACIONALISMOS}

Para atingirmos esses objetivos, adotamos uma metodologia de análise que observa a construção da nação a partir da abordagem modernista, segundo a qual

[...] a nação e o nacionalismo tal como hoje concebemos são produtos da Revolução Francesa, sem nenhum paralelo antes de 1789, por ser um projeto coletivo e por não ter existido antes dessa época uma ideologia segundo a qual o povo soberano compartilha uma história e uma cultura comuns, as quais se devem lealdade e grandes sacrifícios (VIEIRA, 2010, p. 18).

Também consideramos essa abordagem como a mais adequada para o nosso estudo porque

[...] após a Segunda Guerra Mundial, dentro do período que analisamos, a nação é concebida dentro dos valores da Revolução Francesa (autodeterminação, democracia, cidadania, direitos) e é a "terra prometida" do mundo libertado do jugo colonial das potências imperialistas europeias. Além disso, o caminho para a nação dentro dos moldes supracitados também passaria pela industrialização, desenvolvimento econômico (situação dos países centrais). Na América Latina, dada uma situação diferente, por serem países independentes politicamente, mas dependentes economicamente, a afirmação de seus países como nações plenas necessariamente passaria por tal caminho econômico (VIEIRA, 2010, p. 32).

Essa abordagem se baseia nos estudos de Eric Hobsbawm (1991), Benedict Anderson (1989) e Ernest Gellner (1993).

Contudo, a nação não é apenas uma construção subjetiva, ainda que articulada por um projeto político nacionalista. Há uma realidade objetiva, material, sob a qual esse processo se ergue e se impõe - através de mecanismos coercitivos e ideológicos - a partir de imposições político-administrativas dos nascentes Estados-Nacionais burgueses. Isto se torna perceptível nos exemplos históricos 
onde a centralização estatal foi incapaz de articular a fusão das existências protonacionais das identidades localistas em uma versão amalgamada superior de nação, como os impérios Austro-Húngaro e Russo ou o Estado Espanhol. No primeiro caso, a incapacidade levou ao seu esfacelamento após a derrota na Primeira Guerra Mundial. No segundo, apenas sob a hegemonia proletária na Revolução Bolchevique se pôde construir uma forma de convivência entre as nacionalidades, que se esmigalhou com o processo de restauração capitalista. E, no último caso, levou à existência permanente de múltiplas nacionalidades, mantidas sob controle por forte repressão, primeiro pela monarquia, depois pelo franquismo, e que na crise atual volta a apresentar tendências desagregadoras, em particular no caso catalão. A fraqueza das tendências centrípetas levou à consolidação de identidades nacionais alternativas que, à exceção de choques externos (caso austro-húngaro) ou abalos internos (caso czarista e tardosoviético), foram incapazes de construir seu próprio Estado-Nacional.

Há que se entender essa dialética entre nação e Estado-Nacional, que envolve uma relação entre fatores objetivos e subjetivos dessa construção, e que só podem ser explicados pelos agentes político-sociais, de classe, que a dirigem. Nesse sentido, o aporte mais desenvolvido é a análise leninista de interpretação da questão nacional, pois refletirá a partir de uma realidade distinta daquela analisada nos bem-sucedidos casos da Europa Ocidental, e será mais útil para o entendimento dos limites do processo no restante da periferia global. Ela é resumida no trabalho de Stalin, O Marxismo e o problema nacional (1913), publicado no Brasil em coletânea do mesmo autor sobre o tema (STALIN, 1979). Apesar das ponderações feitas por Michael Löwy (2011), há ampla aceitação de que este livro reflete a concepção do conjunto dos marxistas revolucionários russos organizados no Partido Bolchevique, montado sob influência direta de Lênin.

Nesta obra, Stalin distingue materialmente Estado e Nação. Isto é importante pois, ao ter em vista os casos europeus orientais, ele pôde apresentar a autonomia desses dois entes distintos, que os casos de formação e fusão dessas duas realidades no Estado-Nacional europeu ocidental não permitiram aos outros analistas. E, ao afirmar a historicidade da nação, ele se distancia de perspectivas românticas a-históricas do tipo herderiano.

Que é nação?

Uma nação é, antes de tudo, uma comunidade [...] não é comunidade racial ou tribal, mas uma comunidade de homens formada historicamente. [...] não é, pois, um conglomerado acidental e efêmero, mas uma comunidade estável de homens. 
Nem toda comunidade estável de homens constitui, porém, uma nação. A Áustria e a Rússia são também comunidades estáveis e, não obstante, ninguém as qualifica de nações. O que distingue uma comunidade nacional de uma comunidade estatal? (STALIN, 1979, p. 5)

Antes de se prosseguir e responder a essa questão, deve se chamar a atenção para essa imprescindível distinção entre comunidade nacional e comunidade estatal no caso latino-americano, onde distintas realidades coexistem. De um lado, a região centro-americana, uma nacionalidade dividida em seis comunidades estatais (MORENo, 2009), e a América Espanhola, que se fragmentou nos processos de independência por debilidade de sua classe dominante, conformando nacionalidades distintas, "embora semicolonizadas pelo imperialismo norte-americano" (Moreno, 2009, p. 75) e travadas no processo de realização completa de sua comunidade nacional pelas barreiras da dependência. O Brasil, apesar de manter intacta sua comunidade estatal desde a independência (1822), apenas inicia então a construção da nação (com um movimento que tenta afirmar a nação brasileira em oposição a Portugal), reforçada pela Revolução de 1930, e que ainda continua, mas permanece inacabada.

Retornando às elaborações bolcheviques, a nação é "uma comunidade estável, historicamente formada, de idioma, de território, de vida econômica e de psicologia, manifestada esta na comunidade de cultura" (STALIN, 1979, p. 7), e só a existência de todos esses traços ao mesmo tempo estabelece uma nação, ainda que um traço distintivo principal se destaque em cada caso.

Convergindo com as elaborações de Hobsbawm, Anderson e Gellner, Stalin afirma que

A nação não é somente uma categoria histórica, mas uma categoria histórica de uma época determinada, da época do capitalismo ascensional. O processo de liquidação do feudalismo e do desenvolvimento do capitalismo é, ao mesmo tempo, o processo de agrupamento dos homens em nações. Assim acontecem as coisas, por exemplo, na Europa Ocidental [...].

A formação de nações representava ali, porém, e concomitantemente, sua transformação em Estados Nacionais independentes. As nações inglesa, francesa etc. são, por sua vez, os Estados inglês, francês, etc. [...] (STALIN, 1979, p. 13) 
Contudo, como já referido, no caso da Europa Oriental as coisas se deram de maneira diferente, e "no Oriente se formam Estados multinacionais, Estados formados por várias nacionalidades" (STALIN, 1979, p. 13). Stalin apresenta uma explicação material para isto:

Este modo peculiar de formação de Estados só podia existir nas condições de um feudalismo não liquidado, nas condições de um capitalismo debilmente desenvolvido, em que nacionalidades relegadas a um segundo plano não tinham conseguido ainda consolidar-se economicamente para formar nações completas. (Stalin, 1979, p. 13)

Esta será a chave-explicativa que utilizará o marxista catalão e dirigente do POUM (Partido Operário de Unificação Marxista), Andreu Nin, para explicar a realidade espanhola e o movimento de emancipação nacional:

Quando a criação dos grandes Estados correspondeu ao desenvolvimento capitalista e o favoreceu, se constitui um fato progressivo. A formação do Estado alemão, a unidade italiana, para citar apenas dois casos típicos, nos oferecem um exemplo eloquente. Quando a formação dos grandes Estados precede o desenvolvimento capitalista, ou seja, quando se constituem antes que as relações feudais estejam superadas pelas relações burguesas, a unidade resultante é uma unidade regressiva, despótica, de tipo asiático, que atravanca o desenvolvimento das forças produtivas ao invés de favorecê-lo. Por este motivo a luta pela emancipação nacional adquiriu nestes países um caráter tão agudo e uma importância tão enorme como fator revolucionário (Nin, 1935, em livre tradução).

Uma situação parecida se processou mesmo no caso dos Estados Unidos, que para consolidar sua formação enquanto nação e Estado-Nacional precisou de,

[...] entre outras coisas, duas revoluções para completar a tarefa. A revolução colonial, que coroou a primeira etapa de progresso, deu ao povo americano instituições políticas mais avançadas que as de qualquer outro lugar do velho mundo e aplainou o caminho para a rápida expansão econômica. De toda maneira, depois de haver conquistado a independência nacional, os EUA tiveram ainda de conquistar a independência econômica dentro do mundo capitalista. A diferença econômica entre esse país e as nações do ocidente da Europa limitou-se à primeira metade do século XIX e encerrou-se virtualmente com o triunfo do 
capitalismo industrial do Norte sobre os poderes escravistas, na guerra civil. Não foi necessário muito tempo para que os Estados Unidos superassem a Europa Ocidental (Novack, 1988, p. 25).

A história latino-americana seguiu os passos estadunidenses na primeira das revoluções - a anticolonial - adquirindo sua independência política. Contudo, e aqui está a explicação oferecida pela TMD, a independência econômica nunca foi alcançada, devido à inserção histórica dependente do país na economia mundial, o que levou a que não se desenvolvesse - ou quando surgisse, fosse extremamente débil - um setor burguês industrial independente, anti-imperialista, como do Norte dos EUA. Desta maneira, na América Latina, o "Sul" - os setores escravistas e dependentes - venceu o Norte. Por isso, mesmo quando tardiamente se dá o processo de industrialização, a burguesia que emerge mantém esta característica dependente, nascendo deformada e incapaz organicamente de conformar seu próprio espaço territorial econômico independente. Pois "há de existir ainda um vínculo econômico interno que solde num todo único as diversas partes da nação" (Stalin, 1979, p. 6). Contudo, a burguesia dependente não consegue realizar esta soldagem, vinculada que está aos espaços econômicos externos, imperialistas, como se verá à frente.

Sob os limites internos se erguerão limites externos ao desenvolvimento das nações latino-americanas. Curiosamente, como ironia da história, serão os EUA que, se articulando com essa burguesia dependente, atuarão ao longo do século XX para impedir a emergência de um movimento nacionalista popular, que se enfrentará não só com o imperialismo, mas com sua própria burguesia dependente e estéril.

\subsection{ESTRUTURA DO ARTIGO}

A partir dessa abordagem, procedemos nossa análise da seguinte maneira: exporemos sucintamente as transformações da economia mundial sob a hegemonia dos EUA no século XX e início do XXI, dentro da abordagem da economia política do sistema-mundo; depois, a partir dessa reflexão, analisaremos os limites internos históricos e externos à construção da nação e o desenvolvimento da América Latina no período 1970-2010; por fim, teceremos breves considerações finais. 


\title{
2. A HEGEMONIA DOS EUA E AS TRANSFORMAÇÕES NA ECONOMIA MUNDIAL (1970- 2010)
}

\subsection{ANTECEDENTES}

A fim de melhor compreendermos as transformações da economia mundial sob a hegemonia dos EUA no período compreendido entre 1970 e 2010, é necessário que façamos um breve relato a partir do final do século XIX, início do chamado "longo século XX", quando se inicia a hegemonia dos EUA, segundo Arrighi (1996).

Na reflexão de Arrighi (1996, p. 30-31), as hegemonias mundiais surgiram a partir de situações de caos sistêmico:

\begin{abstract}
Historicamente, os Estados que aproveitaram com êxito essa oportunidade fizeram-no reconstituindo o sistema mundial em bases novas e mais amplas, restabelecendo assim uma certa medida de cooperação interestatal. Em outras palavras, as hegemonias mundiais não "ascenderam" e "declinaram" num sistema mundial que se tenha expandido independentemente, com base numa estrutura invariável, definida desta ou daquela maneira. Ao contrário, o sistema mundial moderno se formou e se expandiu com base em recorrentes reestruturações fundamentais, lideradas e governadas por sucessivos Estados hegemônicos.
\end{abstract}

Essas reestruturações são um fenômeno característico do moderno sistema de governo, que emergiu da decadência e eventual desintegração do sistema de governo da Europa medieval.

As funções de governo mundial foram exercidas pelo Reino Unido até o fim do século XIX. De 1870 até a década de 1930 observamos o período da crise sinalizadora (Primeira Grande Depressão de 1873-1896) até a crise terminal do regime britânico de acumulação, com sua perda do controle do equilíbrio de poder europeu e, depois, do equilíbrio global. Nessas perdas, a ascensão da Alemanha à condição de potência mundial foi um fato decisivo. Segundo Arrighi (1996, p. 59):

Ao mesmo tempo, a capacidade do Reino Unido de ocupar o centro da economia mundial capitalista foi minada pela emergência de uma nova economia nacional, de riqueza, dimensões e recursos maiores que os seus. Tratava-se dos Estados Unidos, que evoluíram para tornar-se uma espécie de "buraco negro", dotado de um poder de atração de mão-de-obra, capital e espírito de iniciativa da Europa com que o Reino Unido, e menos ainda as nações menos ricas e poderosas, 
tinham poucas chances de competir. Os desafios alemão e norte-americano ao poderio mundial britânico fortaleceram-se mutuamente, comprometeram a capacidade da Grã-Bretanha de governar o sistema interestatal e acabaram levando a uma nova luta pela supremacia mundial, com uma violência e morbidez sem precedentes.

Nessa disputa pela hegemonia, na qual podem ser incluídas a Primeira e a Segunda Guerra Mundial, os EUA vencem, dado que primeiro conduziram o sistema estatal à restauração dos princípios, normas e regras do Sistema de Vestfália ${ }^{1}$ e posteriormente reformularam o sistema que haviam restabelecido.

Tais restauração e reformulação passaram pela concessão a todos os povos do direito à autodeterminação, ao mesmo tempo em que a provisão da subsistência a todos os cidadãos tornou-se o objetivo fundamental perseguido pelos membros do sistema interestatal. Segundo Arrighi (1996, p. 67):

Em comparação com o imperialismo de livre comércio, as instituições da hegemonia norte-americana restringiram consideravelmente os direitos e poderes de as nações soberanas organizarem relações com outros Estados e com seus próprios cidadãos como lhes aprouvesse. Os governos nacionais têm estado menos livres do que nunca para perseguir seus objetivos por meio da guerra, da expansão territorial e, em grau menor, mas ainda assim significativo, das violações dos direitos civis e humanos de seus cidadãos.

A ONU e as organizações de Bretton Woods, apesar do uso instrumental e da atrofia parcial no momento de expansão máxima da hegemonia mundial norte-americana, não implicaram em um retorno às estratégias e estruturas da hegemonia mundial britânica, pois o "mundo livre" pregado pelos EUA tanto foi uma negação quanto um prolongamento do imperialismo britânico de livre comércio. Ou seja, o imperialismo norte-americano se baseou não em conquistas territoriais externas fundamentalmente, mas em poder de influência através da ideologia do "mundo livre". E o livre comércio constituiu (e constitui) uma estratégia de negociação intergovernamental (bilateral e multilateral) sobre a liberalização do comércio com o objetivo básico de abrir as portas das outras

1 O Sistema de Vestfália foi instituído em 1648 após o fim da guerra de independência das Províncias Unidas em relação à Espanha, instituindo o atual sistema de organização dos Estados e de relação entre eles. Veja-se Arrighi (1996) e Tilly (1996). 
nações aos produtos e às empresas norte-americanos. ${ }^{2}$ Também observamos, até 1973, os anos dourados do capitalismo, dentro da estratégia maior de combate à expansão do socialismo.

Contudo, a arquitetura traçada a partir de Bretton Woods começou a ser modificada nos anos de 1968-73. Nas palavras de Arrighi (1996, p. 310):

A crise iminente do regime norte-americano foi assinalada entre 1968 e 1973, em três esferas distintas e estreitamente relacionadas. Militarmente, o exército norte-americano entrou em dificuldades cada vez mais sérias no Vietnã; financeiramente, o Sistema de Reserva Federal dos Estados Unidos verificou ser difícil e, depois, impossível preservar o modo de emitir e regular o dinheiro mundial estabelecido em Bretton Woods; e, ideologicamente, a cruzada anticomunista do governo norte-americano começou a perder legitimidade no país e no exterior. A crise teve uma deterioração rápida e, em 1973, o governo norte-americano havia recuado em todas as frentes.

Os fatos acima denotam a dinâmica da crise sinalizadora do ciclo sistêmico de acumulação norte-americano, dada a situação de rápida expansão do comércio e da produção mundiais que intensificou as pressões competitivas sobre os principais agentes da expansão e, consequentemente, provocou o declínio dos lucros do capital. Também mostram como as crises militar e de legitimidade do poder mundial dos EUA expressaram a incapacidade de seu aparato militar-industrial de lidar com a descolonização do mundo e a consequente emergência do Terceiro Mundo e seu movimento de países não alinhados (BANDunG, 1955). Tais dificuldades aumentaram com o esfriamento das paixões anticomunistas e a domesticação do poderio soviético. Segundo Arrighi (1996, p. 332): “A razão principal foi que a plena soberania dos países do Terceiro Mundo constituía uma ameaça latente e crescente ao poderio mundial norte-americano, potencialmente muito mais séria do que o próprio poder soviético. Esse desafio era econômico e político”. ${ }^{3}$

2 Sobre a política externa norte-americana, ver Anderson (2015).

3 Sobre o Terceiro Mundo, Arrighi (1996) afirma que, em termos econômicos, sua importância estratégica cresceu como reservatório de recursos minerais e humanos prontos para atender às necessidades presentes e futuras do Primeiro Mundo, dada a grande pressão sobre as reservas mundiais de insumos primários, dentro de um contexto de recomposição da Europa e do Japão à imagem dos EUA, e a corrida armamentista permanente. Porém, em termos políticos, a luta pelo exercício de plenos direitos de soberania dos países do Terceiro Mundo reduziu (em alguns casos eliminou) o uso dos insumos primários desses países por empresas do mundo desenvolvido capitalista. 
Segundo Arrighi (1996), podemos afirmar que o período entre 1930 e meados da década de 1970 pode ser definido como o compreendido entre a crise terminal do regime britânico e a crise sinalizadora do regime norte-americano, explicitada a partir de 1968.

\subsection{A CRISE DA HEGEMONIA DOS EUA A PARTIR DA DÉCADA DE 1970}

No restante da década de 1970, apesar da crise sinalizadora, as estratégias de poder norte-americanas se caracterizam pelo desprezo básico pelas funções de governo mundial, acarretando em uma desestabilização ainda maior do que restara da ordem mundial pós-Segunda Guerra Mundial e em um declínio acentuado do poder e prestígio norte-americanos durante a Revolução Iraniana e a crise de reféns de 1980.

Observamos até 1978 uma política monetária norte-americana frouxa, que incitou o capital a manter a expansão material da economia capitalista centrada nos EUA, mesmo que ela tenha se transformado na causa primária do aumento dos custos, riscos e incertezas para o capital das corporações, em geral, e das empresas norte-americanas, em particular. Tal fato explica porque apenas uma fração da liquidez criada se transformou em novos meios de comércio e produção e a maior fração se transformou em eurodólares e petrodólares.

A partir de 1978, o governo dos EUA passa a adotar política monetária rígida a fim de se acomodar com a comunidade financeira cosmopolita (que cada vez mais buscava ficar fora do controle das autoridades monetárias em mercados fora da Europa). O resultado foi a belle époque da era Reagan (semelhante à Grã-Bretanha eduardiana, à Holanda dos chinós e à Espanha da era dos genoveses), prenúncio do declínio econômico. Quatro medidas acompanharam a redução da oferta monetária norte-americana:

I) elevação das taxas de juros bem acima do índice de inflação corrente, como marco inicial da competição agressiva do governo norte-americano pelo capital circulante mundial;

II) grande impulso de "desregulamentação";

III) início, no governo Reagan, de uma das mais espetaculares expansões do endividamento do Estado na história mundial (apesar de eleito com a promessa de equilibrar o orçamento);

IV) escalada da Guerra Fria com a URSS e exibições de poderio militar contra países inamistosos do Terceiro Mundo (Granada, Líbia, Panamá e Iraque). 
Como em todas as expansões financeiras anteriores, o endividamento do Estado se associou a uma escalada da luta interestatal pelo poder. ${ }^{4}$

Então, dados todos os fatores acima relacionados, entende-se porque, no final da década de 1970, o governo dos EUA abandona a estratégia de confronto com as altas finanças privadas, embutida no New Deal, e busca ajuda por todos os meios disponíveis para recuperar a vantagem na luta global pelo poder. Os resultados foram: i) lucros acima das expectativas; ii) países do Terceiro Mundo colocados numa situação econômico-financeira muito difícil devido às políticas restritivas norte-americanas, as altas taxas de juros e a desregulamentação; iii) prenúncio da crise terminal.

Observamos, desde então, o aumento da frequência das crises econômicas oriundas de ataques especulativos e hipertrofia do sistema financeiro, como observado nas crises do México (1994), Ásia (1997), Rússia (1998), Brasil (1999), Argentina (2001) e EUA (2008), ${ }^{5}$ sendo que esta última ainda trouxe consequências negativas à economia mundial, inclusive com reflexos no país que mais cresceu nos últimos anos, a China. Arrighi (1996) já afirmava que tais situações poderiam ocorrer, dado que vivemos uma situação de caos sistêmico, em que há um processo de transição hegemônica, no qual o sistema de governo, a cada situação dessas, move-se "para frente" e "para trás" ao mesmo tempo, porém, com uma situação inédita: aceleração do ritmo da história capitalista. Segundo Arrighi (1996, p. 80):

Esse movimento duplo e simultâneo, para frente e para trás, também parece caracterizar a atual conjuntura. A diferença em relação aos períodos anteriores de transições hegemônicas é que a escala e a complexidade do moderno sistema mundial já se tornaram tão vastas que deixam pouca margem para novos aumentos. O duplo movimento e a concomitante turbulência podem estar produzindo, portanto, não uma nova reconstituição do moderno sistema de governo em bases mais amplas, porém sua metamorfose num sistema totalmente diferente, que revitaliza um ou outro aspecto dos modos de dominação do começo da modernidade ou mesmo pré-modernos.

4 Segundo Arrighi (1996, p. 328): "E foi a competição pelo capital circulante, ocasionada por essa escalada mais recente na luta interestatal pelo poder, que, mais uma vez, parafraseando Weber, criou as melhores oportunidades para o capitalismo ocidental desfrutar de mais um 'momento maravilhoso' de riqueza e poder sem precedentes".

5 Sobre o caos sistêmico e crise de hegemonia americana, ver Arrighi e Silver (1999) e Wallerstein (2003). 


\section{A CONSTRUÇÃO DA NAÇÃO E 0 DESENVOLVIMENTO DA AMÉRICA LATINA (1970- 2010)}

\subsection{ANTECEDENTES HISTÓRICOS DE LONGA DURAÇÃO}

Os projetos de construção da nação na América Latina foram fortemente atrelados aos projetos de desenvolvimento comandados pelo Estado e iniciados em geral a partir da década de 1930 e intensificados na década de 1950. Isto pode ser afirmado no sentido de que a nação só existe se conquista um espaço econômico interno próprio, algo que as nações latino-americanas nunca alcançaram devido à dependência.

Tendo em vista a questão da conformação nacional, vamos apresentar rapidamente alguns dos argumentos de Ruy Mauro Marini em seu artigo clássico Dialética da Dependência, de 1973. Aqui, Marini aponta as características do desenvolvimento capitalista sui generis latino-americano, "que só adquire sentido se o contemplamos na perspectiva do sistema em seu conjunto, tanto em nível nacional, quanto, e principalmente, em nível internacional" (MARINI, 2005, p. 138). Este caráter peculiar foi engendrado já na etapa da economia agrário-exportadora, mas se ampliará e deixará sua particularidade de ser derivada da insuficiência para ser marcada fundamentalmente pela distorção no capitalismo industrial dependente latino-americano. A constatação essencial é que o "atraso" latino-americano não é um atraso, um "desenvolvimento insuficiente das relações capitalistas [mas] aspectos de uma realidade que, por sua estrutura global e seu funcionamento, não poderá desenvolver-se jamais da mesma forma como se desenvolvem as economias capitalistas chamadas avançadas" (MARINI, 2005, p. 138).

Ao contrário das economias industriais da Europa Ocidental, que desenvolveram primeiro o espaço econômico interno de sua nação, atraindo os excedentes gerados externamente,

[...] a América Latina se desenvolve em estreita consonância com a dinâmica do capitalismo internacional. Colônia produtora de metais preciosos e gêneros exóticos, a América Latina contribuiu em um primeiro momento com o aumento do fluxo de mercadorias e a expansão dos meios de pagamento, que, ao mesmo tempo em que permitiam o desenvolvimento do capital comercial e bancário na Europa, sustentaram o sistema manufatureiro europeu e propiciaram a criação da grande indústria. A revolução industrial, que dará início a ela, corresponde na América Latina à independência política que, conquistada nas primeiras décadas do século 19, fará surgir, com base na estrutura demográfica e administrativa 
construída durante a colônia, um conjunto de países que passam a girar em torno da Inglaterra. Os fluxos de mercadorias e, posteriormente, de capitais têm nesta seu ponto de entroncamento: ignorando uns aos outros, os novos países se articularão diretamente com a metrópole inglesa e, em função dos requerimentos desta, começarão a produzir e a exportar bens primários, em troca de manufaturas de consumo e - quando a exportação supera as importações - de dívidas (MARINI, 2005, p. 140).

Essa trajetória explica, ao mesmo tempo, a extrema desarticulação e os bloqueios para a integração latino-americana, bem como as dificuldades de conformação de um espaço econômico interno e, sendo assim, da conclusão do processo de formação da nação. É a partir de então que

[...] as relações da América Latina com os centros capitalistas europeus se inserem em uma estrutura definida: a divisão internacional do trabalho, que determinará o sentido de desenvolvimento posterior da região. Em outros termos, é a partir de então que se configura a dependência, entendida como uma relação de subordinação entre nações [seria melhor, entre Estados] formalmente independentes, em cujo marco as relações de produção das nações subordinadas são modificadas ou recriadas para assegurar a reprodução ampliada da dependência. A consequência da dependência não pode ser, portanto, nada mais do que maior dependência, e sua superação supõe necessariamente a supressão das relações de produção nela envolvida (MARINI, 2005, p. 141).

A afirmação de que a superação da dependência só pode se dar pela superação das relações de produção que a criam (capitalistas) se coaduna com o entendimento da TMD de que o desenvolvimento latino-americano só é possível com uma revolução socialista. Por conclusão lógica, a realização final das nações latino-americanas só se torna possível no socialismo. Para entender isso, desenvolveremos no ponto seguinte os limites históricos das tentativas de desenvolvimento sem ruptura com o capitalismo, e o papel que os Estados Unidos desempenharam no entrave político-militar-ideológico-econômico a ele. Antes, é preciso explicar por que se torna impossível que as nações latino-americanas sigam o modelo americano de superação da dependência. Isto se explica por dois elementos que tornam inviável um movimento de libertação nacional dirigido pelas burguesias dependentes latino-americanas. 


\title{
3.1.1 LIMITES A UM MOVIMENTO DE LIBERTAÇÃO NACIONAL BURGUÊS NA AMÉRICA LATINA
}

A nação é transpassada pela luta de classes. No caso das nações oprimidas, no entanto, muitas vezes suas burguesias precisam, em sua luta para conformar seu espaço nacional, apelar às suas classes trabalhadoras, para assim poderem superar "a poderosíssima resistência que lhes é oposta pelas camadas dirigentes das nações dominantes" (STALin, 1979, p. 14). Assim se processou em países da Europa Oriental, no final do século XIX e início do XX. A burguesia era o ator principal e, para ela, o problema central era o mercado, isto é, "assegurar 'seu' próprio mercado 'nacional'. O mercado é a primeira escola em que a burguesia aprende o nacionalismo" (Stalin, 1979, p. 14). Contudo, isto nunca se detém em um problema econômico, mas se soma a problemas políticos, como de opressão ao idioma, restrições ao direito ao voto, etc. Em sua luta,

\begin{abstract}
A burguesia da nação oprimida, que se vê acossada por toda parte, entra naturalmente em ação. Apela para 'os de baixo de seu país' e principia a falar de 'pátria', ao pretender fazer da sua própria causa a causa de todo o povo. [...] E 'os de baixo' nem sempre permanecem surdos aos seus apelos, e se agrupam em torno de sua bandeira: é que a repressão de cima também os afeta, provocando o seu descontentamento.
\end{abstract}

Assim começa o movimento nacional (Stalin, 1979, p. 15).

Assim se deu na Europa Oriental entre tchecos, croatas, ucranianos, etc., nem sempre vitoriosos, e nos EUA. Contudo, isto ocorreu na América Latina apenas parcialmente: adquirindo um caráter próximo no processo de independência política, mas muito mitigado nos primeiros passos de industrialização no século $\mathrm{XX}$, e desaparecendo posteriormente. Isto se deve às características da burguesia dependente, sem iniciativa própria, que retira seus privilégios não da conformação de um espaço econômico próprio, mas em associação com o capital internacional.

Porém, também se deve à debilidade do movimento nacional sob uma possível direção hegemônica burguesa, pois "a força do movimento nacional é determinada pelo grau da participação que nele têm as extensas camadas da nação do proletariado e dos camponeses" (STALIN, 1979, p. 15). A marca central da dependência é a impossibilidade da construção de um mercado de consumo interno e, por isso, de articulações progressistas entre a burguesia e as massas proletárias e camponesas, pois a dinamicidade da primeira se dá pela superexploração da força de trabalho. 
Estes elementos se articulam, pois há

separação dos dois momentos fundamentais do ciclo do capital - a produção e a circulação de mercadorias - cujo efeito é fazer com que apareça de maneira específica na economia latino-americana a contradição inerente à produção capitalista em geral, ou seja, a que opõe o capital ao trabalhador enquanto vendedor e comprador de mercadorias (MARINI, 2005, p. 162).

Ou seja, o mercado consumidor da produção dos países dependentes está nos países centrais, sendo coadjuvado pelo consumo de luxo da burguesia dependente e de uma capa reduzida de alta classe média que se forma às expensas e parasitariamente à primeira. Restará aos proletários e camponeses um consumo de subsistência, espremido até níveis inumanos. Isto se dá pois, entre as duas formas de exploração do sistema capitalista - a que se baseia no aumento da força produtiva do trabalho e a que se baseia na maior exploração do trabalho -, a América Latina se inscreve principalmente na segunda (MARTINs, 2011).

Desta forma, não há espaço para a construção de um mercado interno nacional, pois a burguesia dependente não pode criá-lo, integrada que está ao mercado dos países imperialistas. Por isso, da mesma forma que na Rússia cem anos atrás, a tarefa histórica de construção de um mercado nacional e, assim, do último traço central que impede a emergência das nações latino-americanas, não recai mais na burguesia, mas sim no proletariado. Já não se dá mais nos marcos de uma revolução burguesa, mas de uma revolução socialista.

\subsection{ANTECEDENTES HISTÓRICOS DIRETOS (1930-1970)}

Esses projetos de superação do subdesenvolvimento, que tinham como caminho a industrialização através do planejamento estatal, tiveram início com a eclosão da Grande Depressão a partir da crise de 1929 nos EUA, levando as economias latino-americanas, de base primário-exportadora pró-cíclica, cujo centro dinâmico é definido no centro capitalista demandante dos bens primários, a sofrer fortemente seus reflexos. Tal situação levou-as (principalmente as maiores: Argentina, Brasil e México) a se voltarem para dentro e a priorizarem um Processo de Industrialização por Substituição de Importações (ISI ou PSI) que, em um primeiro momento, foi de caráter restringido, isto é, com predominância da produção de bens de consumo não duráveis, tendo, com isso, de depender de exportações de bens primários para obter divisas a fim de importar os bens de consumo duráveis e os bens de produção (máquinas e equipamentos, que inicial- 
mente não foram difíceis de serem obtidos, dado que boa parte era adquirida de empresas falidas dos países centrais devido à Grande Depressão). ${ }^{6}$

Em uma segunda fase, a partir da década de 1950, observamos a intensificação da ISI com o início da industrialização pesada, que até o início da década de 1970 (em especial no Brasil) atingiu o objetivo de desenvolver uma indústria de bens de consumo duráveis e iniciar o desenvolvimento da indústria de bens de capital (ou bens de produção), contando, principalmente no caso da primeira, com grande participação de empresas transnacionais, indo ao encontro do processo de expansão das empresas transnacionais do centro, sob a liderança dos EUA, cuja hegemonia se encontrava em seu auge.

Contudo, se as reflexões sobre o subdesenvolvimento elaboradas a partir do final da década de 1940 com a criação da CEPAL (Comissão Econômica para a América Latina e o Caribe), sob a liderança de Raúl Prebisch, inovaram na reflexão - com os conceitos "relação centro-periferia", "deterioração dos termos de troca", dentre outros, para diagnosticar a situação de subdesenvolvimento da América Latina e propor a industrialização a partir do planejamento estatal com vistas a superar a condição periférica da região -, ainda assim pouco levaram em conta o papel da hegemonia dos EUA nesse processo, que poderia auxiliá-lo ou obstaculizá-lo, como também podemos observar nas reflexões de Furtado no período 1950-1964.

Esse quadro muda a partir da década de 1960, principalmente após o golpe civil-militar de 1964 (com papel central dos EUA), nova conjuntura que será examinada por Furtado em Subdesenvolvimento e Estagnação na América Latina (1966),7 mais especificamente no capítulo "Obstáculos Externos ao Desenvolvimento", o qual analisaremos em seguida.

Segundo Furtado (1966), os obstáculos externos derivam da Guerra Fria, a qual levou a um esforço de definição das áreas de influência dos EUA e da URSS. Nesse processo, os EUA propuseram para a sua área de influência (onde a América Latina estava inserida):

I) Sob Eisenhower: "contenção" da URSS. O pensamento e ação do governo pressupunham que a URSS não somente explorava a revolução mundial, como era a sua criadora;

6 Sobre o início da ISI e do desenvolvimentismo no Brasil, ver Bielschowsky (2000) e Fonseca (2004).

7 Utilizamos a edição de 1968. 
II) Doutrina formulada pelos técnicos do $M I T,{ }^{8}$ sob a liderança de W. W. Rostow (entre o final da década de 1950 e o início da de 1960): os objetivos da política exterior dos EUA seriam melhor alcançados através de uma bem orientada “ajuda externa” aos países subdesenvolvidos, a fim de se alcançar o desenvolvimento e eliminar os riscos de instabilidade social. O resultado prático se deu com a Aliança para o Progresso (APP), ${ }^{9}$ criticada posteriormente pelo establishment norte-americano com a argumentação de que o próprio desenvolvimento, mesmo orientado de fora, cria instabilidade social, pois atinge a estrutura social e a ordem religiosa;

III) Na década de 1960, na esteira da crítica à APP, passou-se a defender a ideia de que não se poderia perder de vista o objetivo da política dos EUA, isto é, de conservar integrada a sua esfera de influência, sendo o desenvolvimento de algum país um meio para alcançá-la. A ajuda teria que ser destinada aos grupos de elite desses países que estivessem empenhados em conservá-los fora do comunismo e do controle soviético. E dentro desses países, se fosse necessário, as forças militares e policiais poderiam ser usadas para assegurar a estabilidade durante a implantação de programas nos moldes da APP.

Portanto, o problema fundamental dos EUA na segunda metade do século XX é o da sua "segurança" e o da América Latina é o do seu "desenvolvimento", dos caminhos de construção da nação. São objetivos conflitivos, não à primeira vista, mas em uma análise mais aprofundada, na qual não pode ser deixado de lado o papel das empresas privadas norte-americanas. ${ }^{10}$ Segundo Furtado (1968, p. 42, grifos colocados):

A partir do momento em que se define a "segurança" dos Estados Unidos como incluindo a manutenção do status quo social na região latino-americana, é perfeitamente claro que a autonomia dos países dessa região (admitindo-se que os povos e os Estados da América Latina não se confundem com ocasionais estruturas de poder) para superintender o próprio desenvolvimento fica reduzida a pouca coisa. Está implícita nessa doutrina que as decisões de caráter fundamental deverão ser tomadas num plano mais alto, provavelmente no

8 Observadas em Rostow (1961) e Millikan e Blackmer (1963).

9 Resposta limitada ao desafio da Revolução Cubana (1959).

10 Isso se constitui em grande novidade na construção do diagnóstico estagnacionista de Furtado, que ele aprofundará nas décadas de 1970 e 1980 e que denomina de transnacionalização do capital, antecipando um dos elementos da análise da mundialização do capital. 
centro político da esfera de influência, ou em algum órgão "supranacional”, cujo poder efetivo constitui simples delegação daquele centro político. [...] [Nesse processo], cabe às empresas privadas norte-americanas um papel básico no desenvolvimento latino-americano e que a execução da política de "ajuda" dos Estados Unidos deve ser principalmente por intermédio dessas empresas. [...]. Acordos de "garantia" vêm sendo assinados com governos latino-americanos pelos quais as empresas privadas norte-americanas, que atuam em determinado país, passam a gozar de situação privilegiada relativamente a idênticas empresas que operam em território dos Estados Unidos.

Logo, a construção da nação corre riscos, como Furtado, numa crítica à tecnocracia (aprofundada na década de 1980), afirma:

Esse "projeto" de desenvolvimento regional, tendente a tornar obsoleta a ideia de nacionalidade como principal força política na América Latina, apresenta muito atrativo para importantes setores das classes dirigentes locais, que veem aí uma fórmula hábil para esvaziar o "nacionalismo", ao qual atribuem grande responsabilidade pela presente inquietação social. Em realidade, se se consegue subtrair ao Estado grande parte de suas funções substantivas na orientação do processo de desenvolvimento econômico e social, seria de esperar que a atual "fermentação" política, que caracteriza muitos dos países latino-americanos, tenda a reduzir-se, passando os governos a atuar principalmente no plano "técnico" (FurTADO, 1968, p. 44, grifos colocados).

O autor, aprofundando sua análise, mostra que implantar esse projeto nas condições históricas da América Latina na segunda metade da década de 1960 seria inviável, pelas seguintes razões:

I) a penetração de grandes consórcios, de elevada inflexibilidade administrativa e grande poder financeiro, tende a provocar desequilíbrios estruturais de difícil correção, tais como: maiores disparidades de níveis de vida entre grupos de população e rápido aumento do desemprego aberto e disfarçado;

II) a redução da capacidade de controle dos Estados nacionais nesse processo leva à acentuação da concentração de atividades econômicas em determinadas subáreas, com o consequente agravamento das disparidades de níveis de vida entre grupos sociais e áreas geográficas; 
III) resultado último: aumento real ou potencial das tensões sociais na região com uma resposta essencialmente repressiva por parte do Estado.

Apesar desse diagnóstico desafiador, Furtado acredita na construção da nação sob a liderança do Estado, porém acrescida do que pode ser o início da defesa da radicalização da democracia nesse processo (que ele desenvolveria com mais ênfase na década de 1980):

O desenvolvimento econômico, nas difíceis condições que enfrenta presentemente a América Latina, requer uma atitude cooperativa de grandes massas de população e a participação ativa de importantes setores dessa população. É por esta razão que as tarefas mais difíceis são de caráter político e não técnico. Uma difícil ação política deverá ser realizada, e isto somente será possível com apoio nos atuais centros do poder político nacional. Ao contrário do que se pretende veicular, o princípio da nacionalidade é vital na atual fase do desenvolvimento latino-americano. Toda autêntica política de desenvolvimento retira sua força de um conjunto de juízos de valor nos quais estão amalgamados os ideais de uma coletividade. E se uma coletividade não dispõe de órgãos políticos capacitados para interpretar suas legítimas aspirações, não está aparelhada para empreender as tarefas do desenvolvimento. Destarte, o princípio da nacionalidade é hoje, ainda mais do que no passado, de extraordinária funcionalidade. Toda medida que se venha a tomar no sentido de enfraquecer os Estados latino-americanos como centros políticos capazes de interpretar as aspirações nacionais e de aglutinar as populações em torno de ideais comuns, terá como resultado limitar as possibilidades de desenvolvimento da região. Assim, a integração econômica latino-americana somente se justifica se for concebida como definição de política comum entre Estados nacionais, e não como articulação entre grandes empresas estrangeiras que operam na região (FurTado, 1968, p. 46, grifos colocados).

Também nesse período destacamos Ruy Mauro Marini (da TMD), com Dialética do Desenvolvimento Capitalista no Brasil (publicado primeiro em espanhol em 1966 e em português em 2000), ${ }^{11}$ no qual chama a atenção para um processo de industrialização brasileiro cada vez mais subordinado ao imperialismo dos EUA, sendo subimperialista sobre os demais países:

11 Utilizamos a edição de 2014 da editora Insular. 
um centro de irradiação da expansão imperialista na América Latina, criando inclusive as premissas de um poderio militar próprio. Nisso se distingue a política externa brasileira após o golpe de 1964: não se trata de aceitar passivamente as decisões estadunidenses (ainda que a correlação real de forças leve muitas vezes a esse resultado), mas de colaborar ativamente com a expansão imperialista, assumindo nela a posição de país-chave (MARINI, 2014, p. 127).

\subsection{A CONSTRUÇÃO DA NAÇÃO E O DESENVOLVIMENTO DA AMÉRICA LATINA DIANTE DA CRISE DA HEGEMONIA DOS EUA (1970-2010)}

Apesar da crise da hegemonia dos EUA a partir da década de 1970, como observamos no item anterior, a América Latina, dado o movimento de mundialização e financeirização do capital, enfrenta dificuldades cada vez maiores para concretizar seus processos de industrialização inseridos na Terceira Revolução Industrial, outro passo importante no caminho fundamental para a superação do subdesenvolvimento e concretização de seus projetos de construção de nação. Observa-se isto em Marini (2000), ${ }^{12}$ ao mostrar as consequências da globalização ${ }^{13}$ para os países dependentes de maneira mais específica, como podemos observar nos pontos do texto que destacamos abaixo (cf. MARINI, 2000, p. 282-284):

I) os países desenvolvidos possuem imensa superioridade em matéria de pesquisa e desenvolvimento, que é o que torna possível a inovação técnica, constituindo-se em um monopólio tecnológico e, por conseguinte, fator de agravamento da condição dependente dos países periféricos;

II) os países centrais controlam a transferência de atividades industriais sobre os países periféricos, tanto por sua capacidade tecnológica como de investimento, atuando: a) pela transferência prioritária aos países dependentes de indústrias menos intensivas em conhecimento; b) pela dispersão entre os diferentes países periféricos das etapas da produção de mercadorias a fim de impedir o surgimento de economias nacionalmente integradas;

12 Publicado primeiro em espanhol em 1997.

13 Segundo Marini (2000, p. 269): "O processo mundial em que ingressamos a partir da década de 80 e que se convencionou chamar de globalização caracteriza-se pela superação progressiva das fronteiras nacionais no marco do mercado mundial, no que se refere às estruturas de produção, circulação e consumo de bens e serviços, assim como por alterar a geografia política e as relações internacionais, a organização social, as escalas de valores e as configurações ideológicas próprias de cada país". Ele ainda destaca quatro aspectos nesse processo (cf. MARINI, 2000, p. 270-272): i) a grande magnitude da população envolvida; ii) a aceleração do tempo histórico; iii) a enorme capacidade de produção que está em jogo; iv) a profundidade e a rapidez dessas transformações. 
III) o resultado dessas ações pode ser observado na divisão internacional do trabalho no nível da produção, na qual os países dependentes regressam ao lugar da divisão internacional do trabalho que ocupavam no século XIX, quando vendiam bens primários para o centro e dele compravam bens manufaturados, mas agora com a utilização de métodos de gestão plenamente capitalistas; IV) a globalização produz, com essa "nova" divisão internacional do trabalho, desníveis crescentes em matéria de saber e de capacitação técnica na mão de obra;

V) a partir do que foi exposto acima, o autor conclui que a globalização contribui para o agravamento da dependência;

VI) para enfrentar tal situação, a solução passa por uma revolução democrática radical, contando com a aliança de trabalhadores do centro e do mundo dependente.

Celso Furtado, observando na década de 1970 que a economia brasileira não continuou estagnada, mas voltou a crescer no período 1968-73, denominado de "milagre" econômico brasileiro, reavalia suas reflexões e inova em sua teoria: elabora o termo "modernização", mantido entre aspas porque não se trata de um processo que leve ao desenvolvimento econômico, mas sim que traz crescimento econômico sem superar a situação de subdesenvolvimento, ${ }^{14}$ dado que se trata de importação de tecnologia dos países centrais nem sempre adequada à realidade periférica da América Latina, além de imitação por parte das classes médias dos países latino-americanos do padrão de consumo das suas congêneres nos países centrais. ${ }^{15}$

Dentro dessas reflexões de Furtado, destacamos Criatividade e Dependência na Civilização Industrial (1978), que pode ser considerado seu livro mais interdisciplinar, onde reforça os aspectos culturais e sociais da "modernização" e da dependência, como observamos abaixo:

I) as estruturas sociais internas na periferia são importantes para a compreensão da industrialização dependente;

II) a "modernização" também significou ocidentalização, isto é, destruição de valores culturais em vários países da periferia sem uma substituição adequada;

14 Como visto, tal posição é defendida pela TMD com mais veemência.

15 Para mais detalhes, ver Furtado (1972; 1974; 1976; 1978). 
III) apesar do quadro negativo na periferia, Furtado (1978, p. 114-116) vê possibilidades de superação:

A luta contra a dependência passa, portanto, por um esforço para modificar a conformação global do sistema. Que se esteja atualmente discutindo essa questão - mais precisamente: que a conformação global do sistema haja sido questionada - é clara indicação de que a relação de forças se está modificando a favor dos países dependentes. Certo: em grande parte dos países periféricos, as relações externas de dependência estão introjetadas nas estruturas de dominação social. Mas, conforme já observamos, isso não impede a emergência de estruturas de poder tecnoburocrático capazes de explorar a nova situação que se está formando. [...] Dentre os recursos de poder em que se assenta a chamada ordem econômica internacional têm particular relevância: a) o controle da tecnologia, b) o controle das finanças, c) o controle dos mercados, d) o controle do acesso às fontes de recursos não renováveis, e e) o controle do acesso à mão de obra barata. Esses recursos, reunidos em quantidades ponderáveis e/ou combinados em doses diversas, originam posições de força, que ocupam os Estados ou os grandes grupos econômicos na luta pela apropriação do excedente gerado pela economia internacional. Essas posições de força são de peso diferente e em seu relacionamento tendem a ordenar-se, produzindo uma estrutura. A luta contra a dependência não é outra coisa senão um esforço de países periféricos para modificar essa estrutura. Coligações de países permitem ocasionalmente obter a massa crítica requerida para o controle de um recurso, ou articular combinações de recursos de alta eficácia na geração de poder.

Outra reflexão importante do autor se encontra em O Capitalismo Global (1998), no qual analisa os efeitos da globalização nos países periféricos (em especial no Brasil), que levam ao aumento da dependência (mantendo o subdesenvolvimento) e propõe alternativas para o enfrentamento dessa situação, como observamos a seguir.

Destacamos primeiramente em sua análise a observação de que as classes dominantes conformaram o modelo de organização societária dentro dos limites ditados pela classe operária (que adquiriram crescente importância como absorvedora do fluxo de produção). Porém, com a globalização, vive-se nova fase dessa luta, em que a organização da atividade produtiva tende a ser planejada em escala multinacional, prejudicando o poder de negociação das classes trabalhadoras, 
reduzindo, portanto, o alcance da ação reguladora dos Estados Nacionais em que se apoiavam as organizações sindicais.

Para Furtado, os novos desafios são de caráter social e não basicamente econômico, exigindo-se imaginação política e utopia. Portanto, para superar o subdesenvolvimento num contexto de globalização, certas condições devem ser cumpridas por qualquer país periférico:

I) grau de autonomia nas decisões que limite o mais possível a drenagem para o exterior do potencial de investimento;

II) estruturas de poder que dificultem a reprodução do padrão de consumo dos países ricos e assegurar um nível relativamente alto de investimento no fator humano, abrindo caminho à homogeneização social;

III) certo grau de descentralização de decisões empresariais para que se possa adotar um sistema de incentivos que assegure o uso do potencial produtivo; IV) segundo Furtado (1998, p. 54): "estruturas sociais que abram espaço à criatividade num amplo horizonte cultural e gerem forças preventivas e corretivas nos processos de excessiva concentração de poder";

Porém, para que tais objetivos logrem êxito, é fundamental o exercício de forte vontade política apoiada em amplo consenso social.

Por fim, vale destacar como sistematização dessa reflexão de Furtado, a sua afirmação de que o desafio posto no início do século XXI é o de mudar o curso da civilização, deslocar o seu eixo da lógica dos meios a serviço da acumulação num curto horizonte de tempo para uma lógica dos fins em função do bem-estar social, do exercício da liberdade e da cooperação entre os povos, da preservação ecológica e com forte participação das sociedades civis (cf. FURTADO, 1998, p. 64).

\section{CONSIDERAÇÕES FINAIS}

A partir do que discutimos neste trabalho, podemos afirmar que, apesar da crise da hegemonia dos EUA, observamos ainda um quadro muito difícil para a América Latina concretizar seus projetos de desenvolvimento e construção da nação, dada a dependência do centro capitalista, tanto tecnológica como culturalmente. Agravando este quadro, tem-se a debilidade das direções proletárias em afirmar um projeto hegemônico alternativo à burguesia dependente, que articulasse um projeto socialista à libertação nacional e à ruptura com o imperialismo e a dependência. 


\section{REFERÊNCIAS BIBLIOGRÁFICAS}

Anderson, Benedict. Comunidades imaginadas. São Paulo: Companhia das Letras, 2009.

Anderson, Perry. A política externa norte-americana e seus teóricos. São Paulo: Boitempo, 2015 .

Arrighi, Giovanni. O longo século XX. São Paulo: Ed. UNESP; Rio de Janeiro: Contraponto, 1996.

Arrighi, Giovanni; Silver, Beverly. Caos e governabilidade no moderno sistema mundial. Rio de Janeiro: UFRJ; Contraponto, [1999] 2001.

Bielschowsky, Ricardo. Pensamento econômico brasileiro: o ciclo ideológico do desenvolvimentismo. $5^{\mathrm{a}}$ edição. Rio de Janeiro: Contraponto, 2000.

Fonseca, Pedro Cézar Dutra. Gênese e precursores do desenvolvimentismo no Brasil.

Pesquisa e Debate - Revista do Programa de Estudos Pós-Graduados em Economia Política, São Paulo, v. 15, n. 2 (26), 2004, p. 225-256.

FurTado, Celso. Subdesenvolvimento e estagnação na América Latina. Rio de Janeiro: Civilização Brasileira, [1966] 1968.

. Análise do "modelo" brasileiro. Rio de Janeiro: Civilização Brasileira, 1972. . O mito do desenvolvimento econômico. Rio de Janeiro: Paz e Terra, 1974.

. Prefácio a nova economia política. Rio de Janeiro: Paz e Terra, 1976.

. Criatividade e dependência na civilização industrial. Rio de Janeiro: Paz

e Terra, 1978.

. O capitalismo global. São Paulo: Paz e Terra, 1998.

Gellner, Ernest. Nações e Nacionalismo. Lisboa: Gradiva, [1983] 1993.

Hobsbawm, Eric. Nações e nacionalismos desde 1780: programa, mito e realidade. Rio de Janeiro: Paz e Terra, [1990] 1991.

Löwy, Michael. O sonho naufragado: a Revolução de Outubro e a questão nacional. Lutas Sociais, São Paulo, v. 7, mar. 2011.

MArini, Ruy Mauro. "Dialética do desenvolvimento capitalista no Brasil”. In: MARINI, Ruy Mauro. Subdesenvolvimento e revolução. Florianópolis: Insular, [1966] 2014, p. 73-161. . "Dialética da dependência". In: Traspadinı, Roberta; StÉdile, João Pedro

(Orgs.). Ruy Mauro Marini - vida e obra. São Paulo: Expressão Popular, 2005, p. 137-180.

. "Processo e tendências da globalização capitalista". In: MARINI, Ruy Mauro. Dialética da dependência. Petrópolis: Vozes; Buenos Aires: CLACSO, [1997] 2000, p. 269-295.

Martins, Carlos Eduardo. Globalização, dependência e neoliberalismo na América Latina. São Paulo: Boitempo, 2011. 
Millikan, Max F.; Blackmer, Donald L. M. (Orgs.). Nações em desenvolvimento: a sua evolução e a política americana. Rio de Janeiro: Fundo de Cultura, 1963.

Moreno, Nahuel. América Central: seis países, uma nacionalidade, uma revolução. Marxismo Vivo, São Paulo, n. 21, 2009.

Nin, Andreu. Els moviments d'emancipació nacional. Barcelona: Edicions Proa, 1935.

Novack, George. A lei do desenvolvimento desigual e combinado da sociedade. São Paulo: Rabisco, 1988.

Rostow, W. W. Etapas do desenvolvimento econômico: um manifesto não comunista. Rio de Janeiro: Zahar, 1964.

Stalin, Josef. O marxismo e o problema nacional e colonial. São Paulo: Livraria Editora Ciências Humanas, 1979.

Tilly, Charles. Coerção, capital e Estados europeus. São Paulo: Editora da USP, [1992] 1996.

VIEIRA, Wilson. O subdesenvolvimento diante da mundialização do capital: uma análise comparativa do pensamento de Celso Furtado e da teoria da dependência. Anais do I Encontro de Economia Política Internacional (ENEPI), realizado de 11 a 13 de maio de 2016, no Rio de Janeiro-RJ.

A construção da nação no pensamento de Celso Furtado. Tese (Doutorado em Sociologia). Instituto de Filosofia e Ciências Humanas. Campinas, 2010.

WALLERSTEIN, Immanuel. Decline of American power: the U. S. in a chaotic world. New York: The New Press, 2006. 